\title{
Assessment of Tuber Viability and Sprouting Behavior of Purple Nutsedge (Cyperus rotundus) - A Prelude Study for Control of World Worst Weed
}

\author{
D. Ravisankar ${ }^{1 *}$, C.R. Chinnamuthu ${ }^{1}$ and P. Srimathi ${ }^{2}$ \\ ${ }^{1}$ Department of Agronomy, Tamil Nadu Agricultural University, Coimbatore-641003, \\ Tamil Nadu, India \\ ${ }^{2}$ Department of Seed Science and Technology, Tamil Nadu Agricultural University, \\ Coimbatore-641003, Tamil Nadu, India \\ *Corresponding author
}

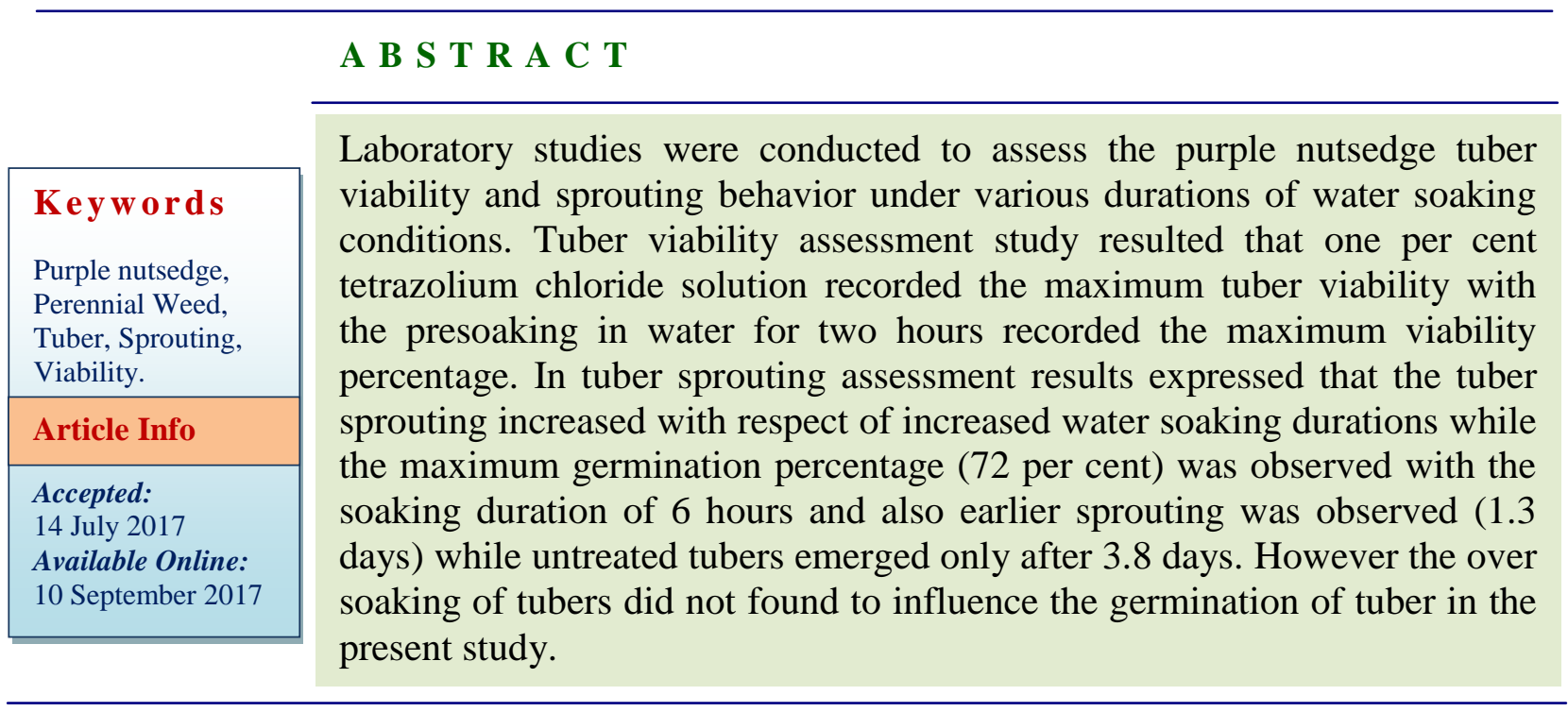

\section{Introduction}

Purple nutsedge (Cyperus rotundus) is a widely distributed weed of agricultural fields in temperate to tropical regions of the world. Purple nutsedge, a species in the Cyperus genera, is considered the world's worst weed and its problem associated with at least 52 crops in 92 countries (Holm et al., 1977). It is highly competitive, fast growing, and prolific. It is a strong perennial weed with a ramifying underground system of interconnected rhizomes and tubers. Its tubers are the storage and perennating organs.
A tuber carries about 1-10 buds concealed in its brown, membranous, scaly leaves. Purple nutsedge basal bulbs and tubers are produced early in its life cycle. Only basal bulbs were produced within the first 3 weeks of the life cycle; tubers were produced in 4-8 weeks, and many tubers were present in chains by 6-14 weeks (Horowitz, 1972). In 3 months, approximately 100 tubers or basal bulbs were produced from plants originating from a single tuber and in 3.5 months, 146 tubers and basal bulbs were formed and in 4 months, 200 
tubers were produced (Jordan-Molero and Stoller, 1978). Because purple nutsedge tubers are formed in chains, an undisturbed field of purple nutsedge growing for a few months could have more than 100 tubers connected in chains.

Cultural practices like field plough, hand weeding, hoeing through implements increase the infestation of these perennial weeds rather than controlling and also cultural control methods such as crop rotation and cultivation (Glaze, 1987) and soil desiccation do not provide sufficient control of this weed. Purple nutsedge has proved difficult to control with herbicides. Chemical control measures provide only poor or temporary control (Pereira et al., 1987) because of limited uptake and translocation of herbicides, and to temporal inhibition of tuber sprouting. All the commercial herbicides available in the market aimed to control or kill the growing above ground part of the weed plants. None of the herbicides are inhibiting activity of viable underground plant parts like rhizome or tubers which act as a source for new plants in the next season.

In tropical condition, Purple nutsedge tuber viability is mainly dependent on the optimum moisture content and its ability to survive within optimum range of temperatures. Moisture content of freshly harvested tubers was around $50 \%$ and tubers were lost its viability when the moisture content was reduced to15\% (Smith and Fick, 1937). Most of the tubers were placed in the upper layer of the soil profile $(15 \mathrm{~cm})$ and very few tubers were below $30 \mathrm{~cm}$, but the roots extended to a depth of $135 \mathrm{~cm}$, also he suggested that the roots were critical in maintaining a water supply for the tubers in the drier upper layers of soil.

Difficulty in nutsedge control is caused by lack of sufficient information on physiological and ecological aspects of tuber sprouting, which determines to a large extent the potential degree of infestation. The prediction of purple nutsedge sprouting could provide an estimate of the tuber reservoir relative to emerged plants, upon which appropriate decisions for management strategies may be imposed. The understanding of tuber dormancy is important and a prelude to devising effective control method for this weed. One approach for an effective control is to stimulate all buds on the tubers to sprout. Much work has been done to manage the purple nutsedge through sprouted above ground plant parts. This study aims to predict the viability of the subsurface tubers and to evaluate the sprouting pattern with respect of different water soaking durations.

\section{Materials and Methods}

Tubers of purple nutsedge were collected in bulk from farmers' field (11 $16^{\prime} 42^{\prime \prime} \mathrm{N}$ $77^{\circ} 35^{\prime} 1^{\prime \prime}$ E) and used as the base material for the study. The tuber viability and sprouting behavior studies were conducted during 2008 at Department of Agronomy and Department of Seed Science and Technology Tamil Nadu Agricultural University, Coimbatore, Tamil Nadu. Tuber viability assessment using
tetrazolium chloride

The tubers of purple nutsedge were washed thoroughly with clean water. Fifty randomly selected tubers of uniform size in four replications were taken and soaked in distilled water for one and two hours. The tubers were prepared for tetrazolium test by giving longitudinal cut. The prepared tubers were soaked in 0.5 and 1 per cent tetrazolium chloride $(2,3,5$ - triphenyltetrazolium chloride) solution and were placed in an incubator maintained at $40^{\circ} \mathrm{C}$ for $10 \mathrm{~h}$. For every one hour the samples were drawn and the viability 
of the tubers were estimated based on staining pattern. The fully stained and stained more than half of the tuber was estimated as viable while unstained tubers as non-viable. The viable and non-viable tubers were calculated using the following formula and mean value expressed in percentage.

Non viable tuber $(\%)=\frac{\text { No. of un stained and stained less than half of tubers }}{\text { Total number of tubers incubated }}$ X100

Viable tuber $(\%)=\frac{\text { No. of stained tubers }}{\text { Total number of tubers incubated }} \times 100$

Preparation specimen for scanning electron microscopy (SEM) (Bozzola and Russell, 1992)

Fresh tubers of purple nutsedge collected from the field were cleaned with triple distilled water and removed all adhering soil particle using soft brush.

The cleaned tubers were sectioned longitudinally and vertically to a smallest possible section using a sharp surgical knife. The section were washed again and fixed with primary fixative glutaraldehide (2.5 per cent) plus $0.2 \mathrm{M}$ sodium cacodylate (buffer) and left 48 hours. Then the samples were washed with the buffer sodium cacodylate to remove the glutaraldehide. Further the samples were fixed with secondary fixative osmimum tetroxide. After three hours of fixation the samples were washed with buffer sodium cacodylate and dried in the CPD to remove all fixative and buffer. The samples were made conductive by coating with golden nanoparticle using sputtering unit. Images of the sections were taken in different magnitude with the help Scanning Electron Microscope model Hitachi S-3400N.

\section{Sprouting behavior assessment experiment}

The tubers collected in bulk were cleaned and washed with water and were soaked for different durations in water. The experiment details are furnished herein.

\section{Duration of soaking}

$\begin{array}{llll}\mathrm{T}_{1} & : \text { No soaking } & \mathrm{T}_{8} & : 210 \mathrm{~min} \\ \mathrm{~T}_{2} & : 30 \mathrm{~min} & \mathrm{~T}_{9} & : 240 \mathrm{~min} \\ \mathrm{~T}_{3} & : 60 \mathrm{~min} & \mathrm{~T}_{10} & : 270 \mathrm{~min} \\ \mathrm{~T}_{4} & : 90 \mathrm{~min} & \mathrm{~T}_{11}: 300 \mathrm{~min} \\ \mathrm{~T}_{5}: 120 \mathrm{~min} & \mathrm{~T}_{12}: 330 \mathrm{~min} \\ \mathrm{~T}_{6}: 150 \mathrm{~min} & \mathrm{~T}_{13}: 360 \mathrm{~min} \\ \mathrm{~T}_{7}: 180 \mathrm{~min} & & \end{array}$

Replication: 3 Design: CRD

The tubers were placed in petri plates adopting top of the paper method (with double layered germination paper) and were kept at $25 \pm 1^{\circ} \mathrm{C}$ and $90 \pm 5$ per cent relative humidity maintained in a germination room in triplicate of 25 tubers each. The petri plates were moistened regularly. Observation was recorded 15 days after sowing.

The growth parameters were recorded during the study viz., sprouting percentage, speed of sprouting, dormant tuber percentage, root and shoot length, vigour index and dry matter production of the sprouted tubers.

\section{Germination (\%)}

The tubers produced normal root and shoot were classified as normal seedling and the number of tubers produced normal seedling after germination period were counted in each treatment and the mean expressed as sprouting/germination percentage (ISTA, 1999).

\section{Days to emergence}

The number of days taken for radical emergence in the tubers placed for the germination was counted from the date of sowing and the mean expressed as whole number. 


\section{Speed of germination}

The number of tubers germinated on each day was counted up to completion of germination. From the number of tubers germinated on each counting day, the speed of germination was calculated adopting the formula of Maguire (1976) and the mean value expressed in whole number.

Speed of germination $=\frac{X_{1}}{Y_{1}}+\frac{X_{2}-X_{1}}{Y_{2}}+\cdots+\frac{X_{n}-\left(X^{-1}\right)}{Y_{n}}$

Where,

$X_{n}-$ Number of tubers germinated at $n^{\text {th }}$ count $Y_{n}-$ number of days from sowing at $n^{\text {th }}$ count

\section{Root length $(\mathrm{cm})$}

At the end of the sprouting/germination period, ten normal seedlings in each of the treatment and replications were selected at random and the distance between collar region to tip of the primary root was measured and the mean values reported in $\mathrm{cm}$.

\section{Shoot length (cm)}

At the end of the sprouting/germination period, ten normal seedlings in each of the treatment and replication were taken at random and the distance between collar region to tip of the primary leaf was measured and the mean values were expressed in $\mathrm{cm}$.

\section{Dry matter production per 10 seedlings (g)}

Ten normal seedlings used for measuring the seedling length were shade dried for $12 \mathrm{~h}$ and then transferred to a hot air oven maintained at $85^{\circ} \mathrm{C}$ for $48 \mathrm{~h}$. The oven dried seedlings were cooled in a desiccator containing calcium chloride for $30 \mathrm{~min}$. and the weight was recorded in an electronic balance. The mean dry matter production was expressed as gram per ten seedlings

\section{Statistical analysis}

The data collected from the laboratory and pot culture experiments were analysed statistically adopting the techniques described by Panse and Sukhatme (1999). Wherever necessary, the per cent values were first transformed to angular arcsine values before analysis. The data were tested at five per cent level for significance and non-significant data were indicated by the letters NS.

\section{Results and Discussion}

\section{Evaluation of tuber viability using tetrazolium chloride}

The purple nutsedge tubers are remain viable for more than two years in field conditions. This is the reason for continuous emergence of this weed in all the seasons. The results of the present experiment recorded 98 per cent tuber viability at 1 per cent tetrazolium chloride solution after six hours soaking with presoaked in water for two hours followed by 96 per cent after seven hours with presoaked in water for one hour. The lowest concentration of tetrazolium chloride solution ( 0.5 per cent) recorded 92 per cent tuber viability after seven hours with presoaked in water for two hours followed by the same level of viability ( 92 per cent) after eight hours with one hour presoaked in water (Table 1). Among the concentrations one per cent of the tetrazolium chloride solution recorded the maximum tuber viability and between the presoaking treatments with water, two hours recorded the maximum viability percentage and the tuber viability was assessed through Scanning Electron Microscope (Fig. 1). The tubers of purple nutsedge serve as the principle means for propagation, survival and spread of the species. The tubers remain viable for more than two years (Neeser et al., 1997). In the present study, the viability of the tubers was ascertained through tetrazolium chloride $(2,3$, 5-triphenyltetrazolium chloride) test which is 
commonly used for identification of viable tissue of biological part based on the staining pattern.

It was observed that ninety eight per cent of the tubers present in the top $15-20 \mathrm{~cm}$ of the soil were viable having the regeneration capacity at one time or other. It could be observed when the tubers were soaked for six hours. Neeser et al., (1997) opined that the tubers of purple nutsedge were highly viable and due to this they exhibit sporadic survival for longer duration that favour the persistency of the weed in the soil causing permanent problem of continuous weed management.

Purple nutsedge tuber viability is dependent on many factors. The most important factor might be the moisture content of the tubers (Smith and Fick, 1937). As and when the water content of the tubers is increased, the tubers start the germination process. It was evident from the experiment, when the tubers collected from the top soil and soaked for 6 hours in water expressed the maximum viability. Lack of sufficient soil moisture in the tropical regions with low rainfall might be the cause for the irregular emergence of purple nutsedge. Further the presence of apical dominance in a chain of tubers also causes irregular emergence and survived under environmental stress. Jangaard et al., (1971) attributed that the presence of inhibitors in the tuber causes the bud dormancy. In contrast based on the attempts to identify the inhibiting substances, Berger and Day (1967) reported that salicylic acid was the major component among many inhibitors found in the foliage of C. rotundus which was not found in the tubers. Thus the present study expresses that the viability of purple nutsedge could be identified through tz staining which could serve as indicator of survival potentiality of the tubers at a particular place of interest.

Influence of different water soaking duration on sprouting of purple nutsedge tuber

The purple nutsedge plant having various degrees of dormancy in tubers, this is the reason for irregular emergence of plant foliage. In general the tubers get sprouted when the tubers attained sufficient moisture content. Understanding the tubers emergence pattern will help us to develop a management technique for the control the purple nutsedge.

Table.1 Purple nutsedge tuber viability in tetrazolium chloride test (\%)

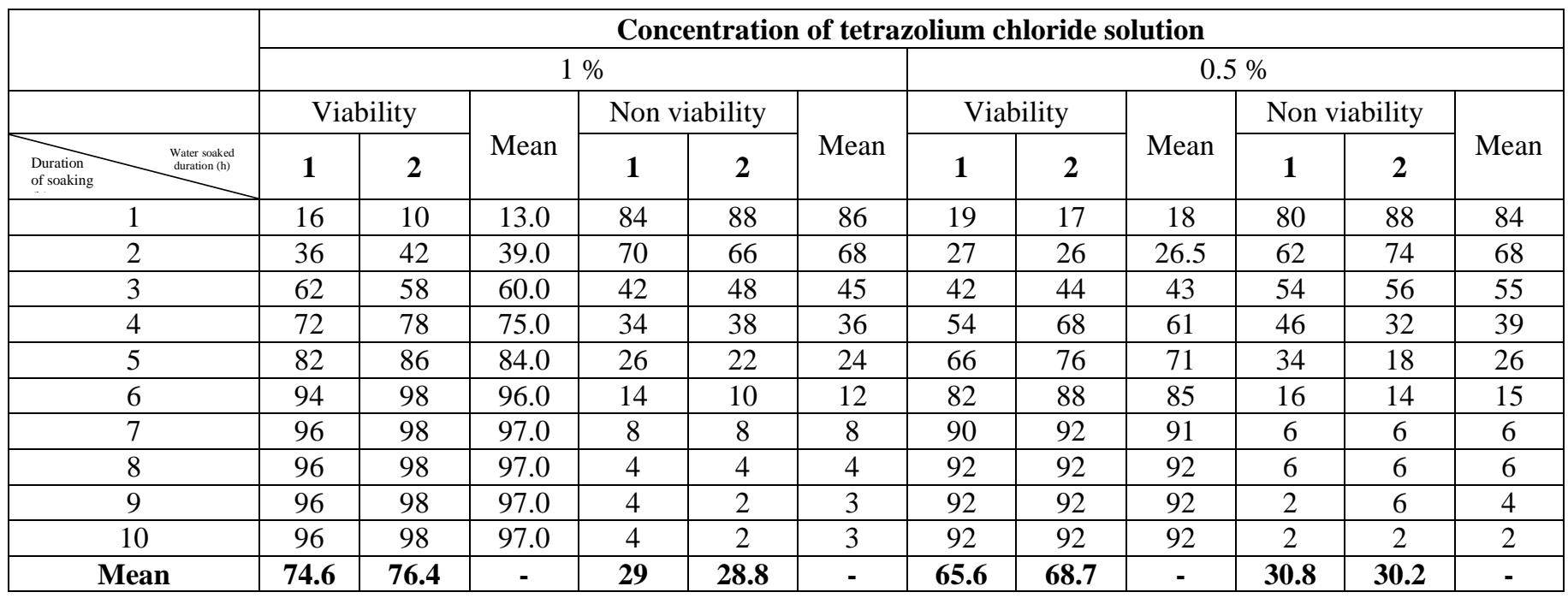


Table.2 Influence of different water soaking durations of purple nutsedge tuber on germination $(\%)$, days to emergence and speed of germination

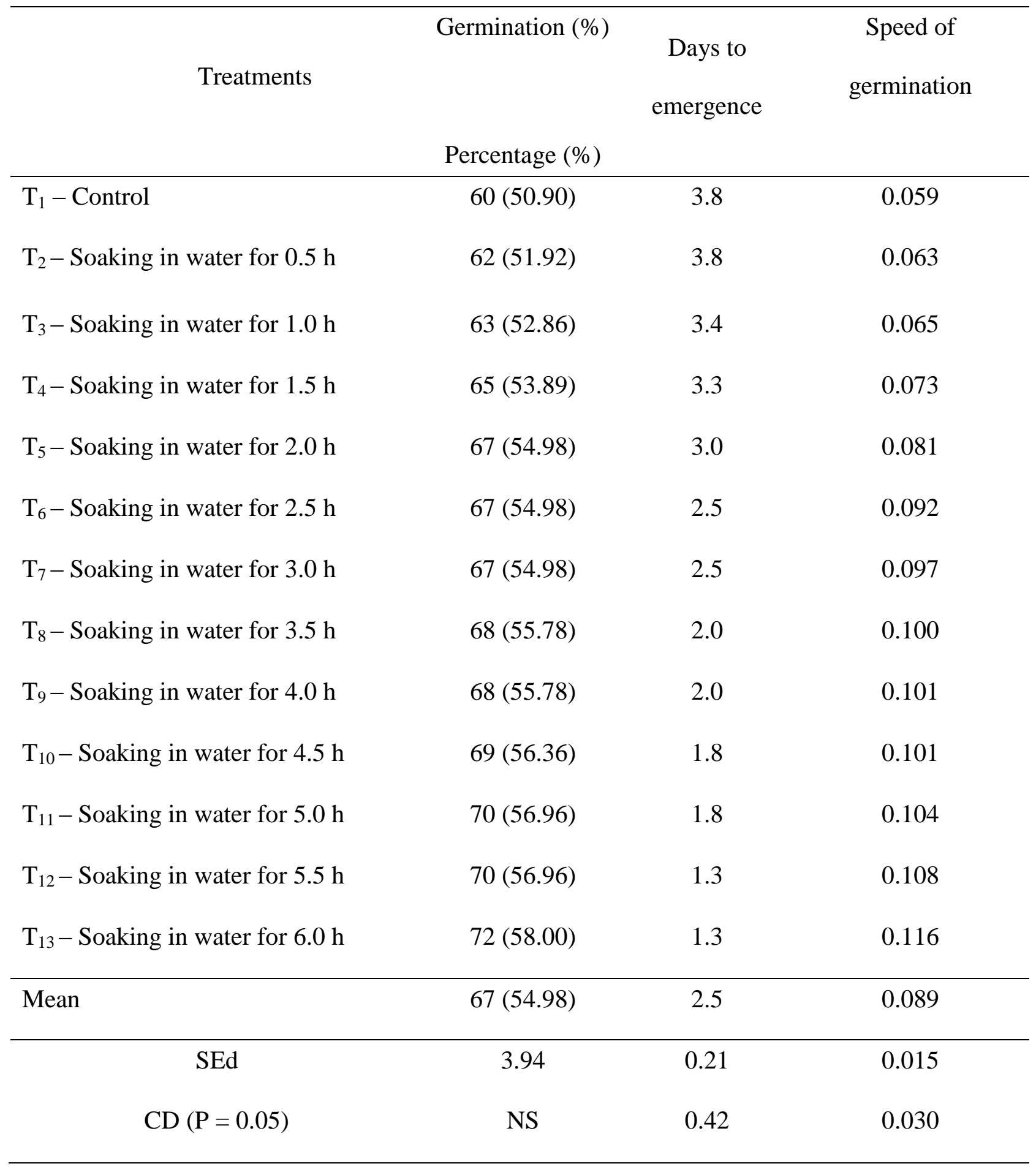


Table.3 Influence of different water soaking durations of purple nutsedge tuber on root length and shoot length $(\mathrm{cm})$

\begin{tabular}{cccc}
\hline Treatments & $\begin{array}{c}\text { Root } \\
\text { length }\end{array}$ & $\begin{array}{c}\text { Shoot } \\
\text { length }\end{array}$ & $\begin{array}{c}\text { Dry matter production } \\
\left(\text { g seedlings }^{-10}\right)\end{array}$ \\
\hline $\mathrm{T}_{1}-$ Control & 3.1 & 4.4 & 2.3 \\
$\mathrm{~T}_{2}$ - Soaking in water for $0.5 \mathrm{~h}$ & 3.3 & 4.2 & 2.4 \\
$\mathrm{~T}_{3}$ - Soaking in water for $1.0 \mathrm{~h}$ & 3.2 & 4.7 & 2.6 \\
$\mathrm{~T}_{4}$ - Soaking in water for $1.5 \mathrm{~h}$ & 3.8 & 5.0 & 2.8 \\
$\mathrm{~T}_{5}-$ Soaking in water for $2.0 \mathrm{~h}$ & 3.6 & 5.2 & 2.8 \\
$\mathrm{~T}_{6}-$ Soaking in water for $2.5 \mathrm{~h}$ & 3.9 & 5.4 & 2.9 \\
$\mathrm{~T}_{7}-$ Soaking in water for $3.0 \mathrm{~h}$ & 4.0 & 5.5 & 3.0 \\
$\mathrm{~T}_{8}-$ Soaking in water for $3.5 \mathrm{~h}$ & 3.9 & 5.6 & 3.1 \\
$\mathrm{~T}_{9}-$ Soaking in water for $4.0 \mathrm{~h}$ & 4.1 & 5.9 & 3.2 \\
$\mathrm{~T}_{10}$ - Soaking in water for $4.5 \mathrm{~h}$ & 4.6 & 5.7 & 3.4 \\
$\mathrm{~T}_{11}-$ Soaking in water for $5.0 \mathrm{~h}$ & 4.9 & 6.0 & 3.3 \\
$\mathrm{~T}_{12}-$ Soaking in water for $5.5 \mathrm{~h}$ & 5.0 & 6.3 & 3.4 \\
$\mathrm{~T}_{13}-$ Soaking in water for $6.0 \mathrm{~h}$ & 5.2 & 6.6 & 3.4 \\
\hline Mean & 4.0 & 5.4 & 3.0 \\
\hline SEd & 0.3 & 0.4 & 0.02 \\
\hline
\end{tabular}

Fig.1 Storage structure present in the viable purple nutsedge tuber (Scanning Electron Microscopic image)

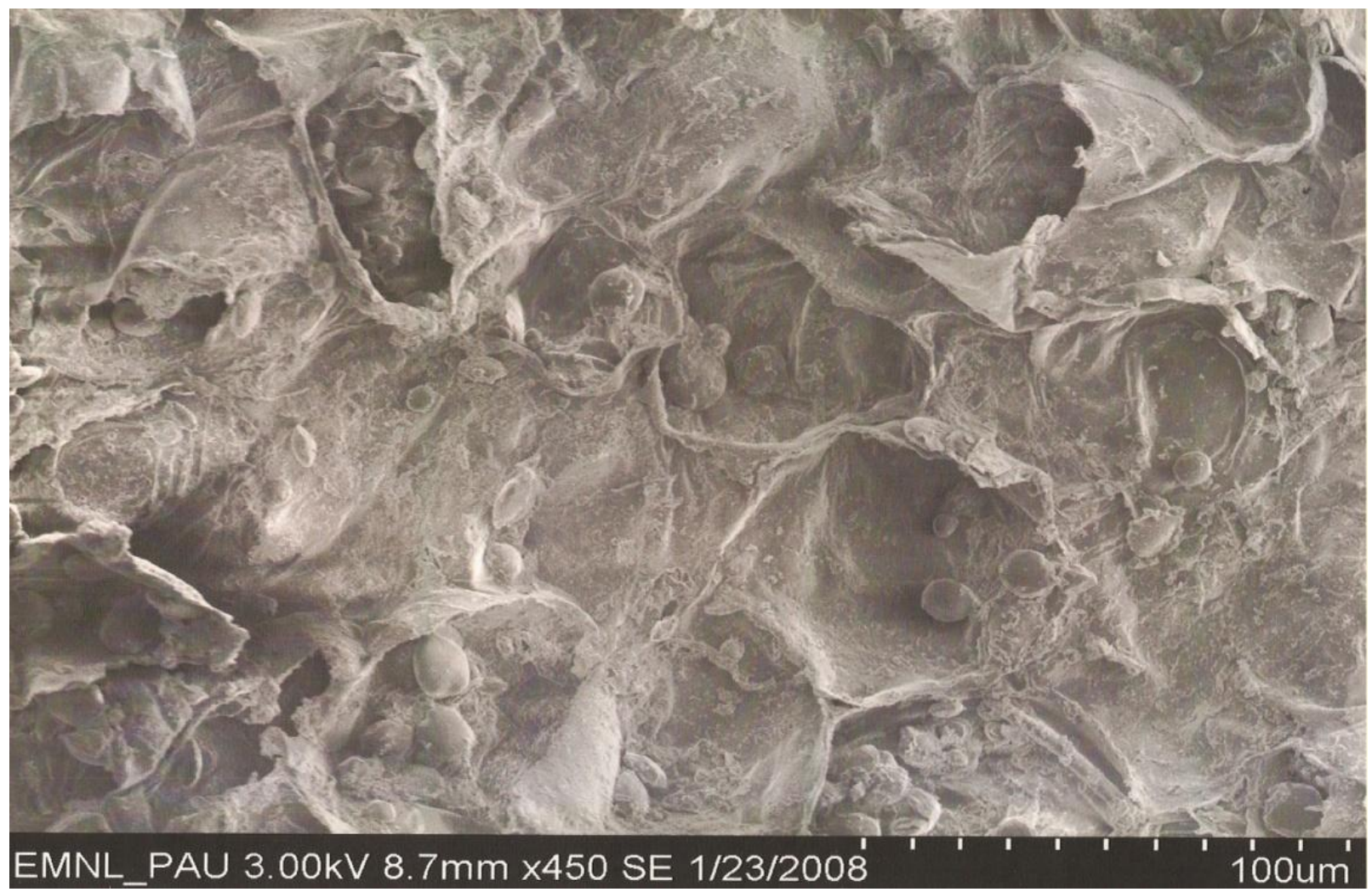


Fig.2 Influence of water soaking durations on purple nutsedge tuber sprouting

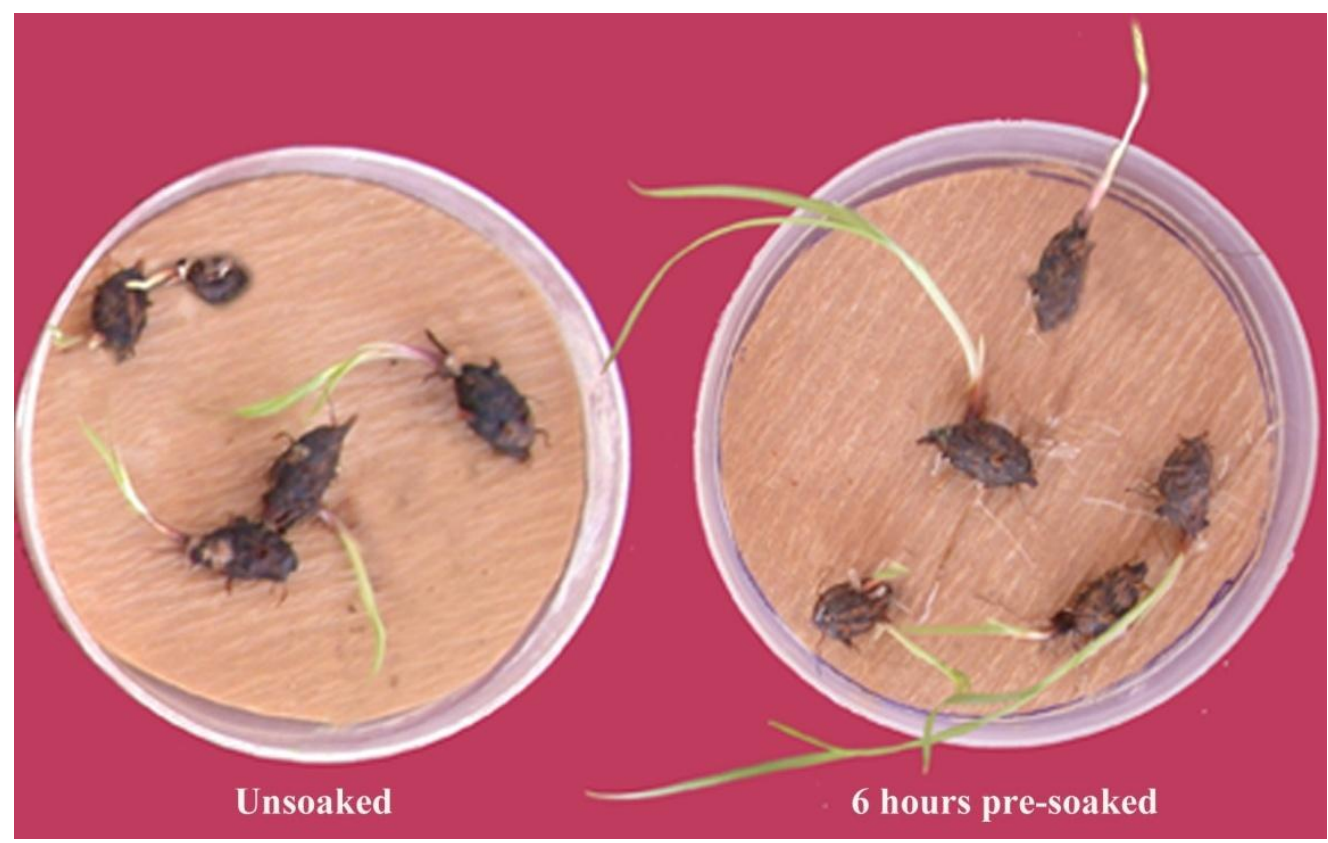

The present experiment was conducted to evaluate the tuber sprouting and growth of purple nutsedge plant with response to different water soaking durations of tubers.

\section{Sprouting (\%)}

The highest sprouting percentage (72 per cent) of tubers was recorded in 6 hour water soaked tubers. The lowest sprouting percentage (60 per cent) was recorded in control. The sprouting percentage was increased with increasing the water soaking duration of tuber. But there was no significant difference observed between the increased rate of sprouting and water soaking duration of tubers (Fig. 2). On identification of viability level of the dormant tuber, it is necessary to identify the germination and dormant status of the tuber in response to the water soaking which would be the basic factor in developing the control measure for any specific weed as weed do germinate and expresses itself after irrigating the field as a general truth. In the present study the tubers were soaked in water for different durations from 1 to $10 \mathrm{~h}$ and evaluated for tuber sprouting under germination chamber condition (ISTA, 1999) adopting top of the paper method.

\section{Growth parameters}

The days to emergence was decreased with the increasing duration of water soaking of tubers. The first emerged purple nutsedge plant was observed in 1.3 days when the tubers were soaked in water for $330 \mathrm{~min}$ and $360 \mathrm{~min}$ durations. Longest time taken for emergence was observed with un soaked tubers (3.8 days). Similarly, Speed of sprouting of tubers was increased with the increasing duration of water soaking. Among the different water soaking treatments, the purple nutsedge tubers soaked in water for $360 \mathrm{~min}$ was recorded the maximum speed of germination (0.116) and the minimum speed of germination (0.059) was observed with control (Table 2).

Soaking of tuber in water for different duration significantly influenced the root and shoot length of nutsedge. Among the different 
water soaking durations, $360 \mathrm{~min}$ water soaked tubers recorded the longest root length of $5.2 \mathrm{~cm}$. The shortest root length $(3.1 \mathrm{~cm})$ was recorded with control and 330 min water soaked tubers. The shoot length of purple nutsedge was significantly influenced by the different water soaking durations of tuber. Among the soaking durations 360 min water soaked tubers recorded the longest shoot length of $6.6 \mathrm{~cm}$. The shortest shoot length of $4.4 \mathrm{~cm}$ was recorded with control. There was an increased shoot length of purple nutsedge with respect to increased level of water soaking durations of tubers. The highest amount of dry matter production of $3.4 \mathrm{~g}$ per 10 seedlings of purple nutsedge recorded with $360 \mathrm{~min}$ and $330 \mathrm{~min}$ water soaked tubers. The lowest amount of dry matter $(2.3 \mathrm{~g}$ per 10 seedlings) production was recorded with control (Table 3).

The results expressed that the tuber sprouting increased with respect of increased water soaking durations while the maximum germination percentage (72 per cent) was observed with the soaking duration of 6 hours and also earlier sprouting was observed (1.3 days) while untreated tubers emerged only after 3.8 days germination improvement of the tuber might be due to the action of water which leached out the inhibitors present in the tubers during soaking and improved the germination of the tubers. The findings of Tumbleson (1962) reported that water washing of tubers before sprouting increased the number of sprouts produced per tuber. Kim et al., (1998) also reported that in Echinochola crusgallivar. Oryzicola seeds dormancy could be broken by simple water soaking which alter the physiology of the seeds. Saraswathi (2004) also reported that water soaking could improve the germination in many weed species. However the over soaking of tubers did not found to influence the germination of tuber in the present study which was also in accordance with the reports of studies that conducted to improve the germination of seed the other propagative material of the plant kingdom. The other evaluated growth parameters like root and shoot length, dry matter production also recorded as maximum with respect of six hours soaking. This might be due to the earlier emergence of the tubers. Hauser (1962) also reported that after the emergence of the tubers, the foliage and root growth were vigourous in purple nutsedge. The emergence of the purple nutsedge in the fields in general, after rainfall or irrigation might be due the sprouting of water soaked tubers. However the specific problem in the purple nutsedge is continuous emergence for longer periods of time. Based on the present study this could be attributed that all the water soaked tubers may not sprout and the unsprouted dormant tubers remain viable in the field.

\section{References}

Berger, G., and Day, B.E. 1967. Dormancy, growth inhibition and tuberization of nutsedge (Cyperus rotundus L.) as attached by photoperiods. In: Proc. Asian-Pacific Weed Control Conf., 1: 123.

Bozzola, J.J., and Russell, L.D. 1992. Electron Microscopy: Principle and Techniques for Biologists, Jones and Bartlett publishers, Boston.

Glaze, N.C., 1987. Cultural and mechanical manipulations of Cyperus spp. Weed Tech., 1: 82-3.

Hauser, E.W., 1962. Development of nutsedge from space-planted tubers. Weeds, 10: 209-212.

Holm, L.G., Plucknett, D.L., Pancho, J. V. and Herberger, J.P. 1977. The World's Worst Weeds. Honolulu, HI: University Press of Hawaii. pp. 8-24.

Horowitz, M., 1972. Growth, tuber formation and spread of Cyperus rotundus L. from single tubers. Weed Res., 12: 348-363. 
ISTA, 1999. International Rules for Seed Testing. Seed Sci. Technology, Supplement Rules. 27: 25-30.

Jangaard N.O., Sckerl, M.M. and Schieferstein, R.H. 1971. The role of phenolics and abscisic acid in nutsedge tuber dormancy. Weed Sci., 19: 17-20.

Jordan-Molero, J.E., and Stoller, E.W. 1978. Seasonal development of yellow and purple nutsedges (Cyperus rotundus and C. esculentus) in Illinois. Weed Sci., 26: 614-618.

Kim, Shim, M.J.T., Lee, S.G. and Kang, B.H. 1998. Studies on the characteristics of germination and emergence of tall parcicum (Panicum dichotomiflorum). Korean J. of Weed Science, 18(2): 146153.

Maguire, J.D., 1976. Speed of germination aid in selection and evaluation of seedling emergence and vigour. Crop Sci., 2: 176-177

Neeser, C., Aguero, R. and Swanton, C.J. 1997. Survival and dormancy of purple nutsedge (Cyperus rotundus L.) tubers.
Weed Sci., 45: 784-790.

Panse, V.G., and Sukhatme, P.V. 1999. In: Statistical methods for agricultural workers. ICAR, Publication, New Delhi, pp. 327-340.

Pereira, W., Crabtree, G., and William, R.D.1987. Herbicide action on purple and yellow nutsedge (Cyperus rotundus L. and C. escidentia L.). Weed Tech., 1: 92-8.

Saraswathi, S., 2004. Studies on Seed Biology in Tropical Weed Species. M.Sc., Thesis Submitted to TNAU, Coimbatore.

Smith, E.V., and Fick, G.L. 1937. Nut grass eradication studies: I. Relation of the life history of nut grass, Cyperus rotundus $\mathrm{L}$. to possible methods of control. J. Am. Soc. Agron., 29: 10071013.

Tumbleson, M. E., and Kommedahl, T. 1971. Reproductive potential of Cyperus esculentus L. by tubers. Weeds, 9: 646653.

\section{How to cite this article:}

Ravisankar, D., C.R. Chinnamuthu and Srimathi, P. 2017. Assessment of Tuber Viability and Sprouting Behavior of Purple Nutsedge (Cyperusrotundus) - A Prelude Study for Control of World Worst Weed. Int.J.Curr.Microbiol.App.Sci. 6(9): 886-895.

doi: https://doi.org/10.20546/ijcmas.2017.609.107 